\title{
Fetal Growth Retardation, CTCAE
}

National Cancer Institute

\section{Source}

National Cancer Institute. Fetal Growth Retardation, CT CAE. NCI Thesaurus. Code C143484.

A disorder characterized by inhibition of fetal growth resulting in the inability of the fetus to achieve its potential weight. 